\title{
A Coin and Something Else: A Rare Case Report
}

\author{
Worood Husain*, Maryam Alderazi, Fatema Alasfoor \\ Department of Otolaryngology-Head \& Neck Surgery, Salmaniya Medical Complex, Manama, Kingdom of Bahrain \\ Email: *drworood@hotmail.com
}

How to cite this paper: Husain, W., Alderazi, M. and Alasfoor, F. (2022) A Coin and Something Else: A Rare Case Report. International Journal of Otolaryngology and Head \& Neck Surgery, 11, 12-17. https://doi.org/10.4236/ijohns.2022.111002

Received: November 20, 2021

Accepted: January 3, 2022

Published: January 6, 2022

Copyright () 2022 by author(s) and Scientific Research Publishing Inc. This work is licensed under the Creative Commons Attribution International License (CC BY 4.0).

http://creativecommons.org/licenses/by/4.0/

\begin{abstract}
Foreign body ingestion in children is considered an emergency. The most common ingested foreign bodies are coins; however, the ingestion of disc batteries is on the rise requiring urgent rigid esophagoscopy. In the literature, multiple foreign body ingestion is very rare and only a few cases of multiple coins and multiple battery ingestion have been reported in the past. Herein, a case of simultaneous coin and battery ingestion requiring foreign bodies removal on two sequential endoscopies due to improper initial evaluation in a pediatric patient is reported which, to our knowledge, is the first reported case.
\end{abstract}

\section{Keywords}

Foreign Body Ingestion, Double Batteries, Double Coins, Disc Battery Ingestion, Esophagoscopy, Second Look Esophagoscopy

\section{Introduction}

Foreign body ingestion is a common upper aerodigestive tract emergency in the otolaryngology practice, particularly in children [1] [2] [3]. Coins are the most common ingested foreign bodies [1] [3] [4] [5], with a recent increase in the incidence of disc battery ingestion [4] [5] that requires urgent rigid esophagoscopy [4] [5]. Multiple foreign body ingestion is very rare [1]. A few cases of multiple coins and double battery ingestion have been reported before [1] [2]. However, to our knowledge this case report is the first reported case of simultaneous coin and battery ingestion in literature.

\section{Case Presentation}

A 16-month-old girl presented to the Emergency Room with complaints of hypoactivity and drooling of a few hours duration after the parents had noticed a missing disc battery at home. She had had vomiting on two occasions but there was no history of chocking, breathing difficulty or cyanosis. The chest $\mathrm{x}$-ray 
(CXR) revealed a round radiopaque shadow in the upper esophagus without the presence of double rings while the lateral neck $\mathrm{x}$-ray showed a step-off appearance of its borders which appeared thick (Figure 1(a), Figure 1(b)). An Urgent esophagoscopy was arranged under general anesthesia through which a coin (25 Bahraini fills) with a diameter of $20 \mathrm{~mm}$ was removed from the cricopharynx (Figure 2). A Second look was attempted but was unsuccessful as the anesthesia was wearing off. Six hours later, the CXR was repeated and showed a smaller radiopaque shadow with double rings at the level of the upper esophagus (Figure 3). Another urgent esophagoscopy was performed through which a disc battery of a smaller diameter than the coin was seen and removed (Figure 4). A second

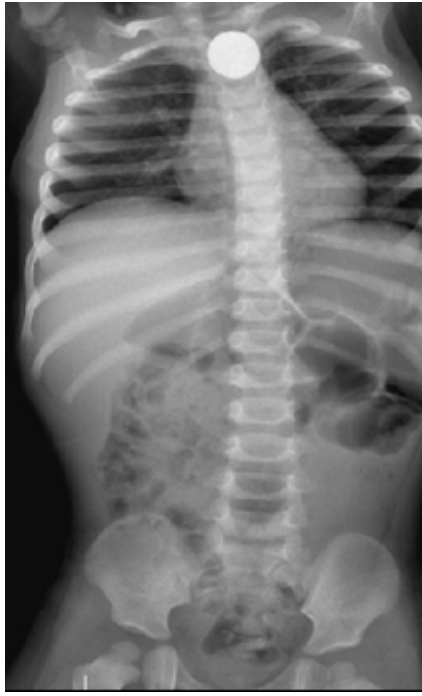

(a)



(b)

Figure 1. (a) Posteroanterior CXR showing round radiopaque foreign body with no halo sign; (b) Lateral CXR with bilaminar step-off sign and increased thickness.

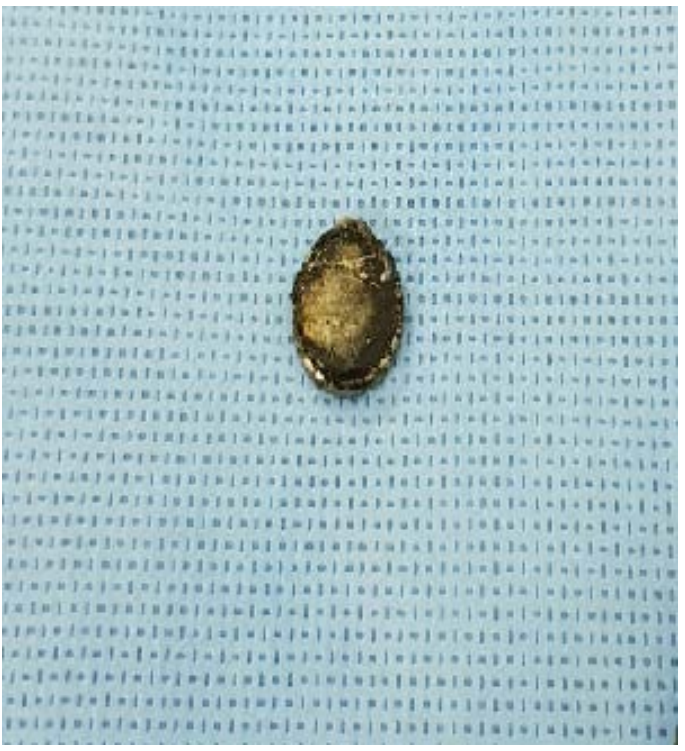

Figure 2. The removed coin. 


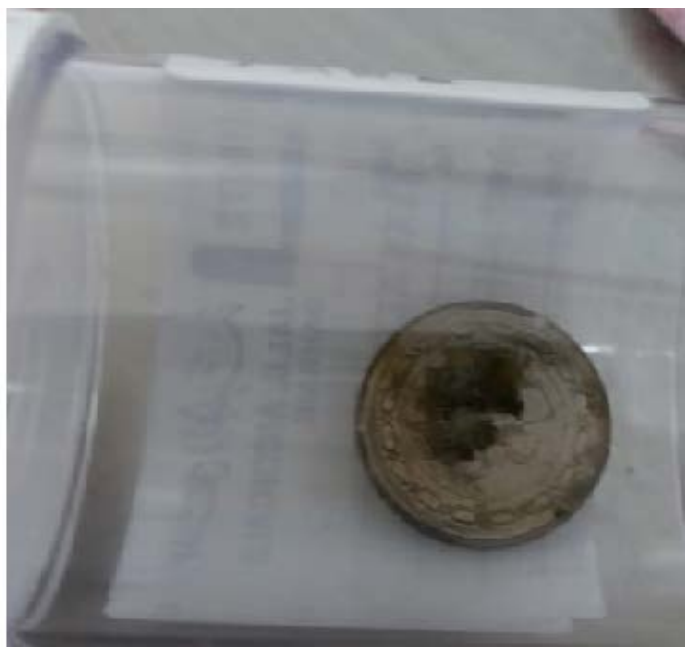

Figure 3. Post-operative CXR showing the halo sign.

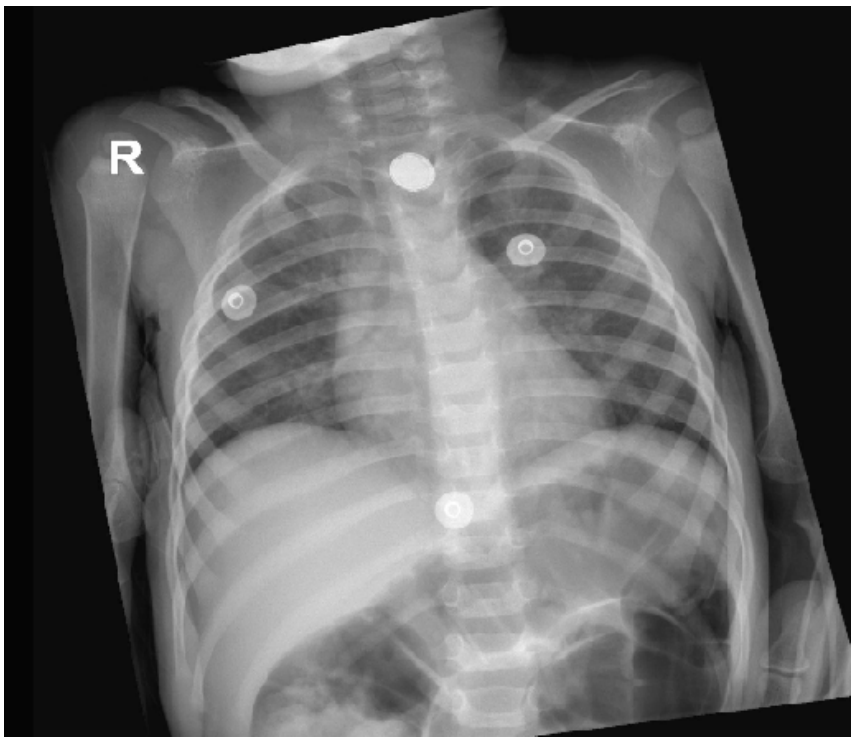

Figure 4. The removed disc battery.

look esophagoscopy showed eschar, erosion, and edema of the esophageal mucosa without the presence of perforation. The patient had been admitted to the pediatric intensive care unit for 48-hours and a nasogastric tube had been kept for one day. She was started on gradual oral feeding. Intravenous antibiotic and a proton pump inhibitor were given. After uneventful hospital stay, she was discharged home on a course of a proton pump inhibitor and a pediatric gastroenterologist review. On a follow-up review, she had no complications.

\section{Discussion and Conclusions}

Foreign body ingestion is one of the most common emergencies in pediatrics below the age of 3 years [1] [2]. Coins are the most common foreign bodies [1]; however, there is a recent increase in the incidence of disc battery ingestion due to the increasing use in the daily life [4] [5]. 
The history in many of these cases may not be reliable because foreign body ingestions commonly occur in young children and are unwitnessed by adults [2] [5]. The nature of the ingested foreign body might not be clear, and the symptoms may be variable [1] [2] [3].

Upper esophagus is the commonest site of foreign body impaction [1] [2] and plain radiographs are necessary to confirm their presence and site of impaction. Poster-anterior and lateral chest views are required [1] [3] [6]. Finding a round radio-opaque shadow on the $\mathrm{x}$-rays is suggestive of either a coin or a disc battery ingestion. Batteries appear as a double ring "halo sign" on the posteroanterior radiographs and have a bilaminar "step-off sign" on the lateral views [4] [5] [7]. The absence of the halo sign on the poster-anterior films should not exclude the possibility of batteries if the step-off sign is seen on the lateral x-rays [4] [5], because the films may be underpenetrated [5]. The step-off sign was found in the rarely reported cases of double coin and double battery ingestions [4].

Rigid esophagoscopy is the preferred method for removing the foreign bodies because it allows a proper examination of the esophagus [1] [2] [6]. A second look esophagoscopy is usually required after removing the foreign body to exclude the presence of a second foreign body and to evaluate the integrity of the esophagus [1] [2]. Some authors recommend requesting postoperative $\mathrm{x}$-rays as well [1] [2].

An observation period of up to 24 hours [1] [2] is advised by many in the case of coin ingestion because coins have a high rate of spontaneous passage and an unusual occurrence of complications which only occur after prolonged impaction [2] [6]. However, there is no dispute that battery ingestion is an emergency and requires immediate esophagoscopy to remove it [4] [6] [7]. Serious complications can occur as early as two hours after the ingestion [4] [6] and are commonly seen in batteries of more than $20 \mathrm{~mm}$ in diameter [4] [5].

The complications associated with the foreign body impaction include stricture formation, tracheoesophageal fistula, esophageal perforation, pneumothorax, pneumomediastinum, pneumonia, mediastinitis, peritonitis or rarely aorto-enteric fistula [4] [6] [7]. These complications are more common with battery ingestion [2] [5].

The ingestion of multiple foreign bodies is very uncommon in the literature. Double coins and double batteries are rarely reported [1] [2]. In this paper, a case of simultaneous coin and disc battery ingestion is reported. To our knowledge, this is the first reported case in the literature about these foreign bodies together. However, the management of the case was unfortunately delayed, despite the suggestive history of battery ingestion, and the unusual radiological findings, that could indicate the presence of a battery or multiple foreign bodies. The removal of a coin during the endoscopy misled the surgeon, who did not insist on a second look, which resulted in missing a serious foreign body. The batteries are known to cause esophageal edema, eschar and bleeding which can make the esophagoscopy technically more difficult [4], especially if the patient is not properly anesthetized. Rigid esophagoscopy is a procedure that requires a 
great deal of communication with the anesthetist [6].

It is obvious that if the preoperative radiographs were properly evaluated and the case was communicated effectively with the anesthetist, the battery was unlikely to be missed initially. Moreover, because of the low index of suspicion, the postoperative x-ray was only repeated hours later. Failure of early recognition of battery ingestion and the delay in its removal, is considered medical negligence in the literature [5]. Fortunately, the recovery of the patient was uneventful which could be contributed to the small diameter of the ingested disc battery of less than $20 \mathrm{~mm}$ [4] [5].

With the information given, otolaryngologist should be aware of the rare possibility of multiple foreign body ingestions and obtain thorough history and examination along with proper radiological evaluation. The importance of a second look esophagoscopy to look for a second foreign body and a proper communication with the anesthetist cannot be overemphasized. Postoperative $\mathrm{x}$-rays might be warranted in some cases.

\section{Declarations}

Ethics approval and consent to participate.

An approval of the Secondary Health care Sub Committee of the Ministry of Health in the Kingdom of Bahrain was obtained.

\section{Consent for Publication}

A written consent was signed by the patient's parent.

\section{Authors' Contribution}

All authors contributed to writing and approving the final manuscript.

\section{Conflicts of Interest}

The authors declare no conflicts of interest regarding the publication of this paper.

\section{References}

[1] Cutajar, J., Astl, J. and Borg, C. (2011) Radiologically Aligned Triple Coin Impaction in the Upper Oesophagus: The Value of Second-Look Oesophagoscopy. International Journal of Pediatric Otorhinolaryngology Extra, 6, 192-194. https://doi.org/10.1016/j.pedex.2010.08.004

[2] Kuhi, S. and Gulati, A. (2014) A “Two-in-One” Foreign Body Coin in Oesophagus: A Case Report. IORS Journal of Dental and Medical Sciences, 13, 65-67. https://doi.org/10.9790/0853-13436567

[3] Takahashi, J., Shiga, T. and Funakoshi, H. (2017) Oesophageal Coins Invisible on Chest Radiography: A Case Report. International Journal of Emergency Medicine, 10, 17-20. https://doi.org/10.1186/s12245-017-0153-8

[4] Littlehales, E., Levi, E., Mills, N., Metcalfe, R. and Hamill, J. (2018) Double Button Battery Ingestion-The "Macaroon" Sign. Journal of Pediatric Surgery Case Reports, 36, 36-39. https://doi.org/10.1016/j.epsc.2018.06.013 
[5] Dawe, N., Puvanendran, M. and Flood, L. (2013) Unwitnessed Lithium Ion Disc battery Ingestion: Case Report and Review of Best Practice Management of an Increasing Clinical Concern. The Journal of Laryngology \& Otology, 127, 84-87. https://doi.org/10.1017/S0022215112002617

[6] Flint, P.W. and Cummings, C.W. (2010) Cummings Otolaryngology: Head and Neck Surgery.

http://www.clinicalkey.com/dura/browse/bookChapter/3-s2.0-B9780323052832X00 $\underline{018}$

[7] McFadden, G., George, P. and Dolan, P. (2021) A Boy with Ambiguous Foreign Body Ingestion. Annals of Emergency Medicine, 77, 119-120.

https://doi.org/10.1016/j.annemergmed.2020.12.021

\section{List of Abbreviations}

CXR: chest-x-ray. 